\title{
La guerra que no tuvo fin: la comunicación del gobierno de Cambiemos*
}

The endless war: Cambiemos' government communication

\section{LUCÍA VINCENT**}

Universidad Nacional de San Martín, Argentina.

lvincent@unsam.edu.ar

https://doi.org/10.46468/rsaap.14.2.A4

El gobierno de Cambiemos en Argentina (2015-2019) desplegó una estrategia de comunicación adaptada a la lógica de los principales medios, que supuso un contraste con el modelo de comunicación controlada de los gobiernos kirchneristas. Sin embargo, la novedosa utilización de las redes sociales implicó una búsqueda por el control de la comunicación, la instalación de temas en la agenda, la elección de los mensajes, las plataformas y los públicos, al tiempo que incluyó una elusión de los medios tradicionales, en especial, de los opositores. Esta estrategia comunicacional, lejos de apaciguar la polarización política y mediática, la mantuvo. Para comprobar esta hipótesis, este artículo se basa en discursos presidenciales, publicaciones periodísticas, medidas de gobierno sobre radiodifusión y seguimiento de redes sociales. A través del estudio de este caso, el artículo busca contribuir a las investigaciones sobre la relación entre los gobiernos y los medios y su impacto para la democracia.

\section{Introducción $^{1}$}

El gobierno de Cambiemos en Argentina comenzó en 2015 con la promesa de que finalizaría el conflicto entre el gobierno y los medios de comunicación, en contraste con el periodo anterior. "Hoy se termina la guerra contra el periodismo y comienza una política pública de comunicaciones del siglo XXI», dijo el jefe de Gabinete, Marcos Peña, en una conferencia de

\footnotetext{
* Artículo recibido el 30 de abril de 2020 y aceptado para su publicación el 15 de octubre de 2020.

** La autora agradece el aporte de dos evaluaciones anónimas a una versión previa de este artículo.

1 Agradezco los comentarios a una versión preliminar de este artículo que recibí de las y los colegas que participaron de las Jornadas sobre "Medios y política en tiempos de polarización", organizadas por Gabriel Vommaro e Ivan Schuliaquer el 9 y 10 de septiembre de 2019(en la UNSAM).
} 
prensa el 31 de diciembre de 2015, al anunciar cambios en la ley de medios a través de un decreto. Si el gobierno de Cristina Fernández de Kirchner había desplegado un conflicto explícito y polarizante con el poder mediático, Cambiemos llegaba generando la ilusión de que comenzaría el fin de la guerra del gobierno contra los medios.

Frente a esta promesa, ¿̇cuál fue el modelo de comunicación gubernamental de Cambiemos y qué diferencias y semejanzas tuvo con otros modelos? Para responder a esta pregunta, propongo dos modelos teóricos de comunicación gubernamental: por un lado, el "modelo de comunicación adaptada", que caracteriza a gobiernos que adoptan medidas favorables a los principales medios y manifiestan una concepción liberal del rol del periodismo como fiscalizador de los actos de gobierno. Por el otro, el "modelo de comunicación controlada", propio de aquellos gobiernos que enfrentan al poder mediático y desconocen o rechazan su rol de control. Estos modelos están asociados a prácticas y discursos que los definen y que permiten ubicar las estrategias de comunicación, en función del grado con el cual responden a estas caracterizaciones.

El argumento que sostengo es que el gobierno de Cambiemos (20152019) llevó adelante un "modelo de comunicación adaptada", resignificado con la incorporación de los nuevos medios digitales, como la estrategia central de la política de comunicación gubernamental. Esta política híbrida le permitió, por un lado, diferenciarse del gobierno precedente, el de Cristina Fernández de Kirchner, que desplegó un "modelo de comunicación controlada" y que mantuvo un fuerte conflicto con los grandes medios considerados opositores (Kitzberger, 2012; Vincent, 2017; De Diego y Fernández, 2019). Por el otro, al incorporar la utilización de las redes sociales como el medio privilegiado de comunicación entre el gobierno y la ciudadanía, supuso una búsqueda por el control de la comunicación, la instalación de temas en la agenda, la elección de los mensajes, las plataformas y los públicos, al tiempo que incluyó una elusión en general de los medios tradicionales y un castigo en particular a los medios opositores. En esta dimensión, se acercó al "modelo de comunicación controlada”, asemejándose al gobierno anterior.

La metodología que sigo en este artículo, supone la formulación del marco teórico-analítico en donde presento las características conceptuales de los modelos de comunicación gubernamental y sus momentos de despliegue en la historia reciente de Argentina. Luego, expongo el caso de la política de comunicación del gobierno de Cambiemos, a la luz de ese andamiaje conceptual: primero, realizo un análisis de contenido de los discursos presidenciales en relación con la comunicación en general y con el rol de los medios masivos en particular, con el objetivo de desentrañar la concepción del gobierno sobre la comunicación y sus consecuencias políticas. Segundo, presento las medi- 
das del gobierno en relación con la comunicación y las políticas de radiodifusión, para determinar su orientación y alcance. Tercero, analizo las prácticas del gobierno para comunicarse con la ciudadanía y, en particular, la utilización de las redes sociales como estrategia principal de comunicación.

Como fuentes utilizo los discursos presidenciales, desde el 10 de diciembre de 2015 hasta el 10 de diciembre de 2019. Del total de 665 discursos que pronunció Mauricio Macri durante su gobierno, se seleccionaron aquellos -41- en los cuales hizo mención tanto al rol de los medios como a las estrategias de comunicación del gobierno ${ }^{2}$. A partir de fuentes secundarias sobre el periodo y de un archivo de prensa, extraigo cuáles fueron las principales medidas del gobierno en relación con la política de radiodifusión. Para el análisis de la relación del gobierno con los medios tradicionales, sigo las publicaciones día por día, durante todo el periodo de gobierno, de tres diarios de circulación nacional con distinta orientación editorial, Clarín, La Nación y Página/12, y la publicación oficial de entrevistas y conferencias realizadas desde la página web de la Casa Rosada. Para el análisis de redes sociales, hice un seguimiento de las cuentas oficiales de Twitter ${ }^{3}$ y Facebook ${ }^{4}$ durante todo el gobierno e incorporé resultados de investigaciones realizadas por especialistas en el tema.

Este artículo pretende ser una contribución a las investigaciones sobre la comunicación de los gobiernos y su relación con los medios, las transformaciones que supone la expansión de las redes sociales y sus consecuencias para la vida democrática. En este sentido, el estudio de este caso busca habilitar las posteriores comparaciones tanto con otros periodos en Argentina como con distintos casos del resto de América Latina y del mundo.

\section{Los modelos de comunicación de los gobiernos: entre la adaptación y el control}

La propuesta teórica que planteo en este artículo es que, en los últimos treinta años, se pueden distinguir en el mundo, y en especial en América Latina, dos grandes modelos antagónicos de comunicación gubernamen-

2 Los discursos presidenciales fueron extraidos de la página oficial de la Casa Rosada (www.casarosada.gob.ar/informacion/discursos), entre 2018 y 2019. Macri habló sobre la comunicación del gobierno en el $6 \%$ de la totalidad de los discursos durante su presidencia.

3 Se analizó la cuenta oficial de Macri en Twitter desde el 10 de diciembre de 2015 al 31 de mayo de 2018. En ese periodo, la cuenta tenía 4.700.026 seguidores y realizó 1882 tweets, un promedio de 2 tuits por día (Datos propios a través de Twitonomy).

$4 \quad$ Se analizó la cuenta presidencial de Facebook desde el 10 de diciembre de 2015 hasta el 10 de diciembre de 2019. Al finalizar el gobierno, la cuenta oficial de Macri en Facebook tenía 4.499.463 seguidores y 4.495.937 "fans" o "amigos". 
tal, que implican una serie de discursos y de prácticas en relación con la comunicación que, además, tienen consecuencias concretas para el vínculo entre los actores del sistema político y para la vida democrática en general ${ }^{5}$. Estos modelos están compuestos por una serie de características que responden a distintas tradiciones, tienen connotaciones ideológicas y suponen una concepción no sólo de la comunicación sino también de la política. Cada gobierno cuenta con un modelo de comunicación propio que evoluciona con el tiempo, condicionado por una serie de factores, y en el que la combinación de características se da según distintos "grados". En los hechos, cada uno se aleja o se acerca más con respecto a los dos grandes modelos de comunicación gubernamental: el "modelo de comunicación adaptada" (MCA) y el "modelo de comunicación controlada" (MCC). El siguiente esquema resume las características de ambos modelos:

\begin{tabular}{|c|c|c|}
\hline & MCA & MCC \\
\hline $\begin{array}{l}\text { Discursos de los } \\
\text { gobiernos sobre } \\
\text { los medios }\end{array}$ & $\begin{array}{l}\text { Escasos discursos } \\
\text { sobre el rol de los } \\
\text { medios } \\
\text { - No mediación entre } \\
\text { el presidente y la } \\
\text { ciudadanía }\end{array}$ & $\begin{array}{l}\text { - Cuestionamiento } \\
\text { público a los medios } \\
\text { - División entre medios } \\
\text { amigos y enemigos } \\
\text { - No mediación entre el } \\
\text { presidente y la } \\
\text { ciudadanía }\end{array}$ \\
\hline $\begin{array}{l}\text { Prácticas de los } \\
\text { gobiernos sobre } \\
\text { los medios }\end{array}$ & 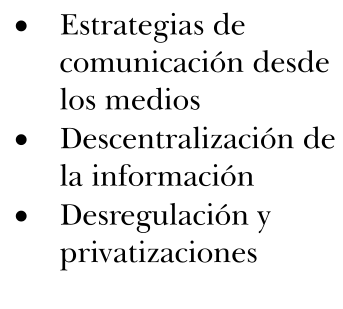 & $\begin{array}{l}\text { - } \text { Estrategias de } \\
\text { comunicación directa } \\
\text { - Control y } \\
\text { centralización de la } \\
\text { información } \\
\text { - Regulación, legislación } \\
\text { y creación de nuevos } \\
\text { medios }\end{array}$ \\
\hline
\end{tabular}

\section{El modelo de comunicación adaptada}

En el último cuarto del siglo XX, en Estados Unidos y Europa se generalizó una crisis de los partidos políticos de masas y un debilitamiento de la democracia representativa, tal como había predominado en las décadas an-

La división entre los "discursos" y las "prácticas" de ninguna manera supone, como dicen Verón y Sigal (2004: 15), que analizar los discursos implique solamente estudiar lo que los políticos “dicen" en oposición a lo que "hacen”, ya que son precisamente los discursos los que permiten identificar los mecanismos significantes que estructuran el comportamiento social, es decir, sólo a través de los discursos cobra sentido lo que los políticos hacen. 
teriores. Esta crisis tuvo su impacto en las formas de hacer política y en las estrategias de comunicación de los gobiernos para mantener la adhesión de la ciudadanía. Durante la década del 90, se extendió entre los principales teóricos de la comunicación política, la noción de que los medios masivos se habían convertido en los principales intermediarios entre el sistema político y la ciudadanía, sustituyendo en cierta medida el papel tradicional de los partidos políticos y constituyendo lo que algunos llamaron una "democracia de audiencias" (Manin, 1997). Autores como Castells (1999), describían una realidad que había llegado para quedarse: una política atravesada por la lógica de los medios, en la que sólo los mensajes políticos adaptados a los códigos de la televisión serían los capaces de atraer la atención de los ciudadanos. Otros autores reforzaban visiones más apocalípticas: Ferry (1992) esgrimía que la política de las ideas estaba dando paso a las identificaciones irracionales y afectivas con líderes personalistas, mientras que Sartori (1998) alertaba sobre el surgimiento de la "videopolítica" en la que el poder de las imágenes imponía una lógica del entretenimiento y la puesta en escena sobre las antiguas prácticas políticas.

En América Latina, con la restauración de las democracias luego de las dictaduras, varios investigadores resaltaron cómo se había extendido en el continente una forma de hacer política signada por el poder de los medios (Verón, 1986; Landi, 1992; Sarlo, 1996), al tiempo que varios estudios desde la ciencia política proponían nociones como la de "democracia delegativa" de O’Donnell (1994): la concentración del poder en un presidente que contaba con la mayoría de los votos, acentuaba los rasgos de personalización de la política, con la utilización de la televisión como mecanismo para establecer una comunicación directa con la ciudadanía, evitando las instancias de mediación tradicionales.

En Argentina, durante el gobierno de Carlos Menem en la década del 90, los medios de comunicación, sobre todo la televisión, adquirieron un protagonismo central en la vida política, con un presidente que se adaptó a la lógica audiovisual y que utilizó a los medios como su forma privilegiada de contacto con la ciudadanía (Quevedo, 1999; Vincent, 2011). Hasta la llegada de Menem al poder, buena parte de la dirigencia política aún concebía a los medios como meros instrumentos de difusión de mensajes (Landi, 1992). Pero Menem comprendió que la televisión se había convertido en el lugar privilegiado de la política en un doble sentido: como escenario y como protagonista del proceso político. La adaptación de Menem a la lógica de la televisión, resultaba funcional a su objetivo de mostrar un vínculo aparentemente no mediado con la opinión pública, desconociendo las mediaciones tradicionales, como los partidos políticos, y en general, a todas las instituciones (Landi, 1992; Sarlo, 1996; Vommaro, 2008). 
Este gobierno se caracterizó por las políticas de radiodifusión que tendieron a la privatización de medios y la consolidación de un sistema de medios concentrado e hipercomercial (Rossi, 2009, Becerra 2010). Las políticas de radiodifusión fuertemente privatistas, sin embargo, no le aseguraron al gobierno de Menem aliados mediáticos durante todo el periodo, sino que agigantaron el poder de esos medios concentrados. El presidente criticó públicamente a los periodistas que llevaban adelante investigaciones en su contra, a los cuales además les inició querellas judiciales (Blanco y Germano, 2005). Sin embargo, las críticas a los medios no fueron un tema habitual de sus discursos, mientras que mantuvo un vínculo estrecho y cotidiano con los periodistas de todas las orientaciones políticas, a los que les respondía preguntas y les brindaba conferencias de prensa (Mochkofsky, 2011). Durante ese periodo, los medios ventilaron numerosos escándalos de corrupción, que monopolizaron las publicaciones de los diarios y los programas de televisión (Waisbord, 2000, Ruiz, 2008). Así, los medios comenzaron a cumplir un rol de control del poder político o de accountability vertical (O’Donnell, 2002), ocupando lugares propios de otros poderes, como la justicia.

El caso del menemismo en Argentina permite construir las características del "modelo de comunicación adaptada", para establecer comparaciones con otros casos. Por un lado, en relación con los discursos de los gobiernos sobre los medios, son escasas o nulas las menciones sobre el rol de los medios de comunicación. Con una admisión tácita del poder que los medios alcanzaron en las prácticas políticas, el discurso gubernamental no nombra a los grandes medios ni los interpela, sino que pretende congraciarse para lograr su favor y, con él, el de la opinión pública. La utilización de los medios como estrategia de contacto directo, cumple el objetivo de la no mediación entre el presidente y la ciudadanía a través de los mecanismos tradicionales, como los partidos políticos o el Congreso. Mientras que el gobierno desconoce a otras instituciones mediadoras tradicionales, habilita a que los medios se transformen en los principales mediadores y, también, en los encargados de controlar al propio gobierno de acuerdo al modelo liberal de prensa.

Por otro lado, las prácticas de los gobiernos sobre los medios implican la participación activa del presidente como un actor más del escenario mediático (en programas de televisión, ofreciendo entrevistas y a través de conferencias de prensa), al tiempo en que se genera una descentralización de la información que no queda solo en manos del presidente. Por último, en cuanto a las políticas de radiodifusión, este modelo supone la desregulación del sistema de medios y las privatizaciones de medios públicos, como mecanismos para beneficiar a grupos de medios que, se espera, tengan reciproci- 
dad en los favores. La consecuencia de este modelo, es la de un gobierno que actúa según la lógica mediática, mientras que los grandes medios adquieren cada vez más poder, beneficiados, además, por las políticas de radiodifusión.

\section{El modelo de comunicación controlada}

Las prácticas de comunicación política de varios gobiernos del mundo sufrieron un vuelco con el comienzo del siglo XXI. En Estados Unidos, los atentados terroristas del 11 de septiembre de 2001 determinaron el surgimiento de nuevas estrategias comunicativas por parte del presidente George Bush, que se extendieron a otros países, como Inglaterra durante el periodo de Tony Blair. Algunos autores, como Panizza (2009), Eco (2010), Mazzoleni (2008) y Fabbrini (2009) comenzaron a utilizar la noción de "populismo" y de "populismo mediático", para caracterizar las nuevas prácticas de los gobiernos en las que se proponía una lectura dicotómica de la realidad privilegiando la antinomia amigo-enemigo y ciertas prácticas de control de la comunicación y de los medios por parte de los mismos. La tendencia en varios países fue la de gobiernos que buscaron volver a controlar la política, limitando el gigantesco poder de los medios.

En América Latina, el fin de la década del neoliberalismo fue de la mano de profundas crisis y de la expansión de cuestionamientos hacia los medios como actores centrales y responsables de muchos de aquellos procesos. El comienzo del siglo XXI estuvo pautado por la expansión de gobiernos de nuevo signo en buena parte del continente latinoamericano, con el ascenso de Hugo Chávez a la presidencia de Venezuela en 1998. Estos gobiernos de "izquierda" o "populistas" tuvieron, como uno de los focos centrales de sus estrategias políticas, una guerra declarada con los principales grupos de medios (Kitzberger, 2012 y 2014; Schuliaquer, 2014; Vincent, 2011 y 2017). Ante un patrón de inestabilidad presidencial en buena parte de América Latina, en el que los medios tuvieron un rol clave en la desestabilización de varios gobiernos (Pérez-Liñán, 2009), algunos de los nuevos presidentes lationamericanos realizaron un aprendizaje por el cual comprendieron que, para lograr mantenerse en el poder, debían conformar un estilo de liderazgo que fuera capaz de controlar a los factores de poder externos, incluidos los medios de comunicación (Vincent, 2017).

Para caracterizar el nuevo vínculo entre gobiernos y medios en América Latina, Waisbord (2014) propuso que con el cambio de siglo se fueron extendiendo en el continente casos de "populismo mediático": al igual que sus predecesores populistas (en referencia a los populismos clásicos de las 
décadas del 40 y del 50), estos gobiernos del siglo XXI comenzaron a pergeñar proyectos para cambiar los aspectos centrales de los sistemas de medios, con el objetivo de limitar al sector privado y favorecer el poder mediático de los gobiernos. La visión populista sobre la relación ideal entre el periodismo y la democracia se basa, desde esta perspectiva, en una concepción binaria de la política, en la cual el mundo esta dividido entre amigos y enemigos. A partir de una valoración crítica sobre el papel de los medios en la democracia, los gobiernos de izquierda comenzaron con estrategias de "activismo mediático" (Kitzberger 2012 y 2014), para desandar el camino de las reformas de mercado de los 90, que dejaron mapas de medios hiperconcentrados.

En Argentina, los gobiernos de Néstor y Cristina Kirchner llevaron adelante una política de comunicación que implicó, por un lado, determinados discursos presidenciales sobre el rol de los medios y, por el otro, prácticas de los gobiernos tendientes a controlar la comunicación con el objetivo de contrarrestar el poder de los medios como intermediarios entre el poder político y la sociedad (Vincent, 2011 y 2017; De Diego, 2014; Fernández, 2014). Durante sus gobiernos, tanto Néstor como Cristina Kirchner pretendieron quitarle a los medios de comunicación, el lugar simbólico de mediadores privilegiados entre el poder político y la opinión pública y buscaron deslegitimarlos en su papel de "cuarto poder" encargado de fiscalizar las acciones del gobierno. A través de sus discursos y con ciertas medidas en materia de radiodifusión, sobre todo durante el gobierno de Cristina Kirchner (Schuliaquer, 2014), el objetivo de estos gobiernos fue desacreditar a aquellos medios o periodistas que se autodefinían como "prensa independiente", para devolverles el lugar histórico reservado a la prensa partidaria (Vincent, 2011; De Diego, 2014).

En sus discursos presidenciales, Néstor y Cristina Kirchner atacaron de manera explícita a los medios que consideraban opositores y pretendieron fijar la agenda de temas de interés público, mediante el control de la información que brindaba el gobierno y los tiempos de difusión. En relación con las políticas de radiodifusión, las medidas fueron ambiguas, ya que durante el mandato de Néstor Kirchner se benefició a los grandes medios (Becerra, 2010), mientras que durante el gobierno de Cristina Kirchner las políticas fueron definidas estratégicamente para limitar a los grandes grupos de medios, en especial, a través de la nueva ley de servicios audiovisuales aprobada en 2009, la creación de medios afines y la distribución de la publicidad oficial, con el objetivo de beneficiar a los medios cercanos al gobierno (Kitzberger, 2014; Schuliaquer, 2014).

Las estrategias desplegadas por el kirchnerismo en Argentina permiten caracterizar el "modelo de comunicación controlada", con discursos que incluyen el cuestionamiento público a los medios, la división entre medios 
amigos y enemigos y la pretensión de no mediación entre el presidente y la ciudadanía (Vincent, 2017). En tanto que las prácticas implican estrategias de comunicación directa (como los programas conducidos por el propio presidente, los actos por distintos lugares del país, las cadenas nacionales), el control o la centralización de la información en manos del presidente, y la regulación, legislación y creación de nuevos medios para lograr acallar las voces opositoras y darles más voz a las afines (Vincent, 2017). La consecuencia de este modelo es la concentración del poder de la comunicación en manos del gobierno con una fuerte polarización con los medios considerados opositores, que son, además, perjudicados por las políticas de radiodifusión.

Entre las características de ambos modelos hay algunas que son comunes, como buscar una comunicación directa con la ciudadanía para lograr su adhesión. En el caso del "modelo de comunicación controlada", se hace "en contra" de los medios, buscando desplazarlos como mediadores indiscutidos entre el presidente y la ciudadanía, mientras que en el caso del "modelo de comunicación adaptada" es "a favor" de los medios, sumándose a la lógica impuesta por ellos con el presidente como un participante más del espectáculo mediático.

\section{La comunicación del gobierno de Cambiemos}

El triunfo de Cambiemos en las elecciones de 2015 supuso el ascenso al poder, por primera vez desde el regreso de la democracia, de una fuerza política de derecha a través de elecciones democráticas (Anria y Vommaro, 2020). Durante la campaña electoral, el candidato Mauricio Macri había prometido que, con su llegada al poder, comenzaría un tiempo de cambio en relación con el periodo anterior. Si los gobiernos de Néstor y Cristina Kirchner tuvieron la originalidad de poner en el centro de la escena a los problemas asociados con la comunicación pública como ninguno lo había hecho desde 1983 (Vincent, 2017), el naciente gobierno de Macri se decidió a enfrentar este legado.

Si bien los integrantes de la coalición "Cambiemos" que llevó a Macri al gobierno no se autoidentificaban con una ideología de derecha o centroderecha, sus principales lineamientos políticos se asociaron con una tradición liberalconservadora y con un paradigma neoliberal (Morresi, 2015). El objetivo de este gobierno fue alejarse de las banderas de la "izquierda" y de la "derecha", mostrarse como una identidad política "posideológica" y "moderna", comprometida con las formas democráticas y republicanas y basada en la construcción de equipos, una gestión seria, honesta y eficaz(Vommaro et al., 2015). 
Sin embargo, la polarización política se mantuvo durante todo el periodo, agravada por la crisis económica (Anria y Vommaro, 2020).

El gobierno de Cambiemos nació en 2015 con una promesa de cambio en relación con el periodo anterior en muchos sentidos, que incluía una novedosa relación entre el gobierno y los medios de comunicación, lejos del conflicto que había caracterizado al gobierno de Cristina Fernández de Kirchner.

A continuación analizaremos cuáles fueron los discursos y las prácticas del gobierno de Cambiemos en relación con la comunicación y con los medios, para compararlos con los dos modelos de comunicación propuestos en el marco teórico.

\section{Los discursos de Macri sobre la comunicación y los medios}

\section{Diferenciación con el gobierno anterior}

Pocos días después de asumir, Mauricio Macri participó de la cena de ADEPA (Asociación de Entidades Periodísticas Argentinas), una institución que nuclea a los dueños de diarios, en donde dijo: "Gracias por la valentía con que defendieron nuestras libertades, la búsqueda de la verdad y espero que lo sigan haciendo en absoluta comunidad, en los próximos años y que ya no haya telarañas en la sala de prensa, como las que encontré en Olivos, cuando lo visité" (Macri, 16/12/2015).

La primera característica de los discursos presidenciales sobre la comunicación, sobre el rol de los medios y sobre el vínculo entre el gobierno y los ciudadanos es que, en casi todos los casos, pretendieron diferenciarse de la administración anterior. Frente a los "ataques" de los gobiernos kirchneristas contra las libertades de prensa y expresión, Macri se ubicaba del lado de las "víctimas", a las que les prometía un nuevo tiempo de "búsqueda de la verdad" en un clima de "absoluta comunidad" (Macri, 16/12/2015).

$\mathrm{Al}$ hablar de la libertad de prensa frente a dueños de medios, este concepto se identificaba con el de libertad de empresa, como si fueran dos principios inescindibles. En varias oportunidades, Macri reiteró la broma sobre la situación con la que se encontró la sala de prensa en la residencia presidencial de Olivos, en referencia a otra característica del gobierno anterior que él pretendía dejar atrás. Así, reafirmaba su concepción sobre el vínculo que se debía establecer entre gobierno y medios, respetando ciertas prácticas, como las conferencias de prensa, asociadas con el modelo de periodismo liberal anglosajón.

El gobierno anterior se caracterizaba, según Macri, por no respetar el "valor de la palabra" y por "discursear" mucho, apelando a "datos falsos" 
(Macri, 16 /12/ 2015). En su primer mensaje de inauguración de las sesiones del Congreso en marzo de 2016, dijo que el gobierno previo había sido el de la "mentira", el que confundía la "realidad y la fantasía", el que de manera sistemática "confundía" a todos para lograr sus objetivos. En contraposición, el nuevo gobierno sería el de la "verdad", el que generaría confianza y credibilidad a través de la información que el Estado brindaría a cada ciudadano. Frente a un Estado mal gestionado, sin estadísticas, sin documentación, con "instrumentos de navegación rotos", se levantaba un Estado "transparente" y "ordenado", que mostraría "la realidad tal cual es" (Macri, 1/3/2016).

En varios discursos, Macri sostuvo que su gobierno respetaría los datos y los hechos con el objetivo de reconstruir la "confianza", algo que en su concepción resultaba imprescindible para atraer las inversiones necesarias que aseguraran el crecimiento económico y, así, "solucionar la pobreza en nuestro país" (Macri, 5/5/ 2016). Del respeto a la libertad de expresión se saltaba así a la generación de confianza para fomentar las inversiones, claves para un crecimiento económico basado en la apertura de la economía y en la atracción de nuevos capitales. El liberalismo político y el liberalismo económico se presentaban como las dos caras de una misma moneda.

En contraste con el gobierno anterior, el de Cambiemos era, desde el discurso presidencial, un gobierno que respetaba la libertad de expresión, sin "medios adictos que manipulen la información a su favor" ni presiones a periodistas para que difundan "las versiones oficiales" (Macri, 22/10/2018). La libertad de prensa, en contraste con el periodo anterior, suponía que el gobierno no gastara enormes cifras de dinero público en propaganda política y que el presidente no realizara cadenas nacionales "atacando a quienes piensan distinto y bajando línea”. Por su parte, los medios debían realizar sus investigaciones periodísticas con la colaboración del gobierno y las voces opositoras debían tener espacio en los medios estatales "sin restricciones, porque una sociedad se desarrolla cuando la diferencia no se combate" (Macri, 22/10/2018).

La de Cambiemos era una política construida desde la oposición a un pasado que era necesario dejar atrás, haciendo exactamente lo que se suponía sería lo contrario. El gobierno de Fernández de Kirchner había llevado a la sociedad a un conflicto permanente, en donde quienes opinaban distinto padecían "persecuciones" y "descalificaciones" (Macri, 1/3/2017). En oposición a ese periodo, el gobierno de Macri, desde su perspectiva, inauguró un periodo de "diálogo" como una manera de entender la política. De la pretensión hegemónica del discurso kirchnerista, se pasaba, así, a una etapa de "diálogo" entre quienes pensaban diferente, como forma de construcción política. 


\section{El rol de los medios}

En determinadas ocasiones, Macri explicitó cuál era el rol que le asignaba a la prensa. Mientras que al gobierno le tocaba "hacer muchas cosas", a la prensa le correspondía el rol de fiscalizar las acciones del gobierno, a través de una "crítica constructiva" (Macri, 16/12/2015). Es decir, que ese control que debía ejercer la prensa tenía ciertas condiciones: no debía ser una simple oposición al gobierno, sino que su intención tenía que ser la de aportar constructivamente para que, así, el gobierno pudiera "siempre mejorar". De este círculo virtuoso entre gobierno y medios, donde cada uno "hace lo que hay que hacer" ${ }^{\prime}$, resulta un vínculo "constructivo", más allá de si el gobierno estuviera de acuerdo o no con lo que publicaran los medios. En definitiva, de eso se trataba una democracia "vital y con instituciones fuertes" 7 .

Macri hacía un reparto de roles en el vínculo entre medios y gobierno, en el cual el papel principal le correspondía al propio presidente, pero en donde los medios debían asumir también un papel clave siguiendo el guión: el presidente diría la "verdad" y sería "breve, conciso y preciso" (Macri, 16/ 12/2015). Mientras tanto, los medios debían "investigar con rigor" y "publicar todo lo que se necesita saber", siguiendo las consignas que postula el modelo de prensa independiente, por el cual los medios son los encargados de fiscalizar las medidas del gobierno a través de procedimientos establecidos de investigación para que sus resultados sean válidos, publicando todo lo que sea "necesario", más allá de posibles líneas editoriales (Macri, 16/12/ 2015).

Que cada actor en este reparto siguiera su papel resultaba imprescindible, según Macri, para que se recuperara la confianza y, de esa manera, se asegurara el crecimiento en la Argentina. Les exigía a los dueños de medios que adoptaran el compromiso patriótico de contribuir al desarrollo del país haciendo bien su trabajo, que no era otra cosa que no "buscar catorce explicaciones", sino informar sobre qué está haciendo el gobierno en cada momento, algo que no debería dar lugar a interpretaciones diversas: "si decimos blanco, sepamos que es blanco" (Macri, 16/12/2015).

Macri explicitaba en sus discursos cuáles eran los lineamientos de su política de comunicación: el respeto de los mecanismos tradicionales de

\footnotetext{
Uno de los eslóganes de campaña gráfica del gobierno de Macri fue el que postulaba: "Haciendo lo que hay que hacer". Para un análisis de este eslogan, ver Montero, 2018.

7 En relación a esta idea, en un documento difundido por la Jefatura de Gabinete en marzo de 2018, se afirmaba: "Reconocemos que en ocasiones discrepamos con la cobertura de algún episodio, pero eso no sólo es normal: es deseable. En una democracia vital y con instituciones fuertes, una prensa que no incomoda al Gobierno, que no esta atenta a llamarle la atención sobre sus errores o contradicciones, es una prensa que no está haciendo bien su trabajo" (Jefatura de Gabinete, 2018).
} 
vínculo entre gobierno y prensa a través de las conferencias de prensa y las entrevistas a periodistas, la rendición de cuentas y la pluralidad en los contenidos de los medios pertenecientes al sistema público y en las ofertas culturales del Estado ${ }^{8}$. Desde el discurso presidencial, los medios públicos no debían ser "herramientas partidarias o ideológicas" (Macri, 1/3/2017), en una distinción clásica entre medios públicos y medios partidarios o de gobierno.

En una oportunidad, Macri hizo alusión a aquellos que "agredían" al gobierno, en contradicción con la posición abierta a la escucha y al diálogo manifestada en otros discursos. Si bien no nombraba a los medios críticos, los incluía al hablar en general de quienes cuestionaban a su gobierno. Desde el discurso presidencial, aquellos que "agredían" al gobierno lo hacían desde sus miedos o inseguridades, por no comprender el camino que estaba emprendiendo este gobierno junto con "gente que hace muchos años no creía en nada". Frente a estas "agresiones", el presidente proponía que el gobierno y sus aliados mantuvieran la "autoestima" y ejercitaran la "capacidad de aislarse", sin perder "energía" y siguiendo con el foco en lo que tenían "que hacer" (Macri, 20/4/2016). El presidente asumía una posición en la que aseguraba que no sería permeable a las críticas hacia su gobierno, con la convicción de que, lo que movilizaba a los agresores, eran sus propias inseguridades. Él, por su parte, mantendría la autoestima y la claridad del rumbo elegido.

\section{Comunicar es informar}

En los discursos presidenciales de Macri una idea se mantuvo constante: la noción de que el Estado debía ser transparente y brindar información para que cada ciudadano pudiera ejercer el control de sus acciones a través de Internet. Esta concepción iba de la mano de la política de Gobierno Abierto y con el impulso de la ley de Información Pública, como dos herramientas imprescindibles para lograr este objetivo de transparencia, para "que todos sepamos qué se hace desde el Estado, porque el Estado funciona gracias a nuestros recursos, a los impuestos que pagamos todos" (Macri, 22/ 2/2016). Estas políticas se mostraban como la contracara de lo que había

Cuatro días antes de finalizar su gobierno, Macri sostenía lo siguiente: "Vivimos cuatro años de libertad total de expresión y de prensa. Sin guerra contra el periodismo ni ataques del Gobierno a quienes piensan distinto. Es un logro colectivo que nos merecemos mantener. En estos años jamás critiqué a un periodista ni desmentí una información que me pareció incorrecta. También se acabó con nosotros el uso de la publicidad oficial como una herramienta para premiar o castigar a los medios." (Macri, 6/12/2019). 
sucedido durante el gobierno anterior, caracterizado por el ocultamiento de la información estatal.

La comunicación que el gobierno de Cambiemos proponía a los ciudadanos era, por un lado, un Estado emisor que hacía visibles sus datos y estadísticas y, por el otro, un ciudadano receptor que utilizaba esa información para ejercer su control fiscalizador. El mensaje era información aséptica, verdadera, objetiva y confiable. Mientras tanto, los mediadores tradicionales, en especial los medios, pasaban en este esquema a un segundo plano, en una comunicación sin mediaciones entre el Estado y el ciudadano a través de internet como el canal privilegiado.

Desde esta perspectiva, la información que brinda el Estado carece de interpretaciones posibles, de polémica y de la necesidad de la argumentación. Si el gobierno postulaba que su estrategia para gobernar era "hacer lo que hay que hacer", en materia de comunicación su correlato era "informar lo que hay que informar".

\section{La búsqueda de la proximidad}

Al vínculo que se debía establecer entre el Estado y los ciudadanos a través de internet, el gobierno debía sumar un encuentro cara a cara, para "escuchar" lo que estos ciudadanos tenían para decir, fundamentalmente, de las políticas estatales que esperaban que el gobierno llevara adelante: "La Argentina ha vuelto al diálogo. Los funcionarios de mi gobierno y yo personalmente seguimos tocando el timbre para escuchar directamente lo que la gente nos tenga para decir" (Macri, 1/3/2016).

Ese diálogo que postulaba el presidente se concretaba, en la práctica, a través de una de las estrategias tradicionales de la campaña permanente: el "timbreo" como una estrategia de proximidad (Annunziata, 2018). Era en estas visitas a distintos hogares que el presidente se nutría de las demandas de la ciudadanía, en un vínculo directo sin intermediarios, con un gobierno que pretendía acercarse a "la gente" desde la empatía y la emoción. Durante esos encuentros, el presidente escuchaba "las dudas, miedos y angustias", a las que su gobierno prometía responder.

Se pasaba entonces de un Estado que transmitía información "objetiva" a través de datos transparentes, a un gobierno que se acercaba a la subjetividad de cada individuo al que visitaba, sin lugar para las demandas colectivas, agregadas o mediadas por partidos políticos, sindicatos, organizaciones sociales o medios de comunicación tradicionales. La centralidad de la comunicación estaba puesta en la comunicación directa entre el gobierno y los ciudadanos a través del uso de las nuevas tecnologías. Cada 
individuo, desde su dispositivo, recibía "información fidedigna" del Estado y, de esa manera, tenía la capacidad de controlarlo. La fiscalización dejaba de estar en manos del cuarto poder, para distribuirse, potencialmente, entre todos los ciudadanos.

\section{Las prácticas de comunicación del gobierno de Cambiemos}

\section{Las políticas de radiodifusión}

Apenas Macri asumió, comenzaron una serie de cambios respecto de las políticas de radiodifusión. Primero, se creó el Ministerio de Comunicaciones y se modificaron las leyes de servicios audiovisuales y de telecomunicaciones a través de la intervención de AFSCA (Autoridad Federal de Servicios de Comunicación Audiovisual) y AFTIC (Autoridad Federal de Tecnologías de la Información y la Comunicación). Ambas autoridades de aplicación quedaron unificadas en el Ente Nacional de Comunicaciones (Enacom). Además, se creó el Sistema de Medios y Contenidos Públicos, por encima de Radio y Televisión Argentina (Becerra, 2016; Califano, 2018).

Estas medidas, adoptadas por decretos, modificaban la ley de servicios audiovisuales aprobada por amplias mayorías en el Congreso en 2009 y cuya constitucionalidad fue ratificada por la Corte Suprema de Justicia en 2013. El nuevo Ministro de Comunicaciones, el radical Oscar Aguad, afirmó que esta ley no iba a "subsistir" durante el nuevo gobierno porque su único objetivo había sido "aniquilar al Grupo Clarín”. En cambio, comenzaba una etapa en la que la "libertad de expresión va a ser absoluta" y en donde "los medios van a tener que competir como se compite en el mercado" (Abrevaya, $2015)^{9}$.

El gobierno de Cambiemos flexibilizó algunos de los artículos de la ley de medios que restringían la venta de medios audiovisuales, la integración de cadenas privadas de radio y televisión y las restricciones a la propiedad cruzada de television por cable. Se permitió, además, la extensión de los plazos de licencia por diez años, sin importar su fecha de vencimiento. Por último, se estableció que las empresas de telefonía pudieran ingresar a la televisión paga dos años después. El objetivo era establecer un nuevo marco regulatorio convergente, que rigiera por igual para todos los actores de la comunicación, provinieran de las telecomunicaciones o de los medios audiovisuales (Becerra, 2016; Califano, 2018).

En julio de 2017, el gobierno de Macri eliminó el Ministerio de Comunicaciones, pasando la comunicación a la órbita del Ministerio de Modernización (Abrevaya, 2017). 
El argumento central del gobierno de Macri para impulsar estas medidas fue que las leyes de medios y telecomunicaciones habían quedado obsoletas en relación con el avance de la tecnología, por lo que era necesario establecer un solo mercado de las comunicaciones donde confluyeran las empresas telefónicas y las de televisión por cable y donde todas compitieran en la provisión de servicios, incluidos la telefonía móvil e internet. De esta manera, la flexibilización de ciertas disposiciones tenía el sentido de revertir una política del gobierno anterior considerada como arbitraria por parte del gobierno entrante (Crettaz, 2015; Abrevaya, 2015). Desde el comienzo, mediante decretos el gobierno tuvo una tendencia a favorecer la libertad de empresa, como sinónimo de la libertad de expresión, una concepción ampliamente discutida. Esta política tuvo el sentido de "restaurar" (Becerra, 2016) para volver a la etapa anterior a los gobiernos kirchneristas, desmantelando las regulaciones, el modelo de financiamiento y los conflictos en las relaciones entre el ejecutivo y los principales medios.

Numerosas fueron las voces en contra de los decretos impulsados por el gobierno de Macri. Los argumentos centrales se basaron, por un lado, en el procedimiento: la modificación de una ley aprobada por el Congreso a través de un decreto de necesidad y urgencia. Por el otro, en cuanto a los contenidos: la flexibilización de los límites a la concentración de la propiedad favorecería a los medios más grandes, justamente lo que pretendía contrarrestar la ley de medios aprobada por el Congreso (Becerra, 2016). De esta manera, en lugar de impulsar la competencia y la convergencia entre sectores -como se postulaba-, las medidas adoptadas promovieron "la protección y la consolidación de las grandes empresas que ya gozaban de una posición dominante en el mercado infocomunicacional argentino" (Califano, 2018: 49).

A su vez, el gobierno de Macri prometió el establecimiento de criterios de distribución de la publicidad oficial públicos y transparentes, sin la arbitrariedad que caracterizó, desde su perspectiva, a la política del gobierno anterior. El gobierno de Cambiemos disminuyó la cantidad de fondos asignados a la publicidad oficial por considerar que este presupuesto era demasiado abultado durante la administración precedente ${ }^{10}$. Además, dispuso, a través de una regulación de agosto de 2016, una distribución de la publicidad oficial de acuerdo a criterios que el propio texto calificaba como de "objetivos": el alcan-

10 Según datos oficiales, en 2016 se redujo el presupuesto de publicidad oficial a casi la mitad de lo gastado el año anterior: de 2.200 millones de pesos a 1.300 millones de pesos. En 2017 se mantuvo constante en términos reales y para 2018 se asignó un presupuesto de 1.800 millones de pesos, que en términos reales (ajustado por inflación) representaba un descenso de más de la mitad frente a los niveles de 2015 (Jefatura de Gabinete, 2018). El 6 de diciembre de 2019, a cuatro días de terminar el gobierno y por cadena nacional, Macri dijo que la publicidad oficial se había reducido en un $70 \%$. 
ce del medio, la pertinencia del mensaje, la zona geográfica y el fomento del federalismo y la pluralidad de voces. Más allá de la apelación a la pluralidad de voces y la federalización, la distribución en la práctica de la publicidad oficial privilegió el criterio del alcance del medio, por lo que se vieron beneficiados los medios con mayor circulación y llegada, como el Grupo Clarín. Si bien se redujo el presupuesto para la publicidad oficial, aumentó la concentración de medios que recibieron pauta (Marino y Espada, 2017).

El macrismo avanzó sobre otros aspectos que pretendieron desandar la estrategia del gobierno anterior en los siguientes aspectos: la consolidación del «Gobierno Abierto», por el cual la información del gobierno y las estadísticas se encontraban disponibles para todos los ciudadanos, y el impulso legislativo de la ley de acceso a la información pública, que fue aprobada por unanimidad en septiembre de 2016 y que estableció que todas las dependencias del Estado (incluyendo además a las empresas públicas, los partidos políticos, las universidades y los sindicatos que recibían aportes públicos), estuvieran obligados a responder a consultas de cualquier ciudadano en un plazo máximo de un mes.

Por su parte, la designación de responsables de los medios públicos se realizó siguiendo criterios profesionales y la programación de estos medios pretendió mostrar una pluralidad de voces. Más allá de las discusiones públicas que se generaron por el desplazamiento o despido de periodistas de sus cargos $^{11}$, el gobierno de Cambiemos pretendió darle un sentido de profesionalismo, en lugar de privilegiar la orientación política de las personas nombradas ${ }^{12}$.

\section{Estrategias de comunicación del gobierno}

El gobierno de Cambiemos pretendió establecer una diferencia con el periodo previo en las prácticas de comunicación que llevó adelante: brindó conferencias de prensa, ofreció entrevistas, recibió a corresponsales extranje-

11 El gobierno de Macri fue cuestionado por la oposición por "el despido o retiro voluntario de 2700 trabajadores en Buenos Aires, según datos del Sindicato de Prensa de ese distrito. El sistema de medios y producción de contenidos estatal perdió más de la mitad de las audiencias con las que contaba hasta 2015 y fue la empresa que más trabajadores despidió (Tiempo Argentino, "Cierres y despidos: un ciclo con menos voces. 15 de abril de 2019).

12 La carta de la Jefatura de Gabinete de marzo de 2018 afirmaba que en la televisión pública se dio un proceso de renovación hacia contenidos plurales, que reflejaban todas las voces y todas las regiones del país. En 2017, el 54\% de los invitados a los programas políticos de la televisión pública fueron representantes de la oposición, según un relevamiento interno de Radio y Televisión Argentina (RTA). 
ros, estableció voceros que tenían un vínculo diario con los periodistas y habilitó a los ministros a que hicieran declaraciones públicas ${ }^{13}$. Estas medidas implicaron un reconocimiento de las prácticas periodísticas y de las relaciones entre gobiernos y medios propias del modelo de comunicación adaptada.

Sin embargo, en el caso de las entrevistas presidenciales ofrecidas a distintos medios, se distribuyeron de acuerdo a una selección favorable al gobierno. En prensa, se privilegiaron los medios más afines al oficialismo ${ }^{14}$, como La Nación y Clarín. En televisión, las entrevistas que brindó Macri fueron principalmente para programas conducidos por periodistas amigos y a través de canales cercanos al gobierno ${ }^{15}$. En radio, se dio prioridad a las emisoras del interior del país a donde el presidente iba de gira, con una selección realizada de antemano por el propio equipo de comunicación oficial ${ }^{16}$.

Si bien el gobierno de Cambiemos buscó diferenciarse del periodo anterior a través del ofrecimineto de entrevistas a medios tradicionales, la distribución de a quiénes se les otorgaron esas entrevistas, mostró un privilegio de los medios afines, en detrimento de los opositores. Este gobierno mostró también una clara vocación por marcar la agenda pública de temas y por establecer los tiempos y las formas de la comunicación de la agenda. La

13 Entre diciembre de 2015 y marzo de 2018, Macri brindó 73 conferencias de prensa y 133 entrevistas exclusivas a medios nacionales e internacionales. El jefe de Gabinete, Marcos Peña, participó en 84 conferencias de prensa y dio 94 entrevistas (Jefatura de Gabinete, 2018). La Cadena Nacional de Radio y Televisión se usó seis veces durante todo el gobierno: el día de la asunción, para los discursos de apertura de sesiones del Congreso de 2016, 2017 y 2018, para la transmisión de las celebraciones del Bicentenario de la Declaración de Independencia, el 9 de julio de 2016; y el 6 de diciembre de 2019, como cierre del gobierno.

14 Del análisis de las tapas de tres diarios nacionales durante todo el periodo de Cambiemos, se desprende lo siguiente: el presidente brindó entrevistas a La Nación (20/3/ 2016; 8/11/2016; 2/6/2017; 22/2/2019) y a Clarín $(19 / 11 / 2016 ; 14 / 5 / 2017 ; 2 / 6 / 2017$; 22/2/2019). No se observan entrevistas a Página/12.

15 Según los datos de Casa Rosada (www.casarosada.gob.ar), Macri brindó las entrevistas para televisión en los siguientes programas: "Animales Sueltos" de Alejandro Fantino en América TV (21/07/2016 y 23/12/2017); "Hablemos de otra cosa" con Pablo Sirvén de la LN+ (1/11/2017); "La Cornisa" de Luis Majul en América TV (17/03/2018 y 18/ 03/2019); "El diario de Mariana" con Mariana Fabbiani de Canal 13 (21/3/2018); "Código Político" con Eduardo Van der Kooy y Julio Blanck en TN (26/04/2018); "Periodismo para todos" con Jorge Lanata por Canal 13 (17/06/2018); "Desde el llano" con Joaquín Morales Sola en TN (3/12/2018); "Nada personal" de Viviana Canosa en Canal 9 (22/04/2019). Además, brindó entrevistas a canales de televisión del interior y cadenas internacionales, como CNN, Bloomberg y Televisión Española.

16 Según datos oficiales (www.casarosada.gob.ar), Macri ofreció 45 entrevistas en radio durante su mandato. De ese total, tres fueron para radios nacionales: Radio Mitre (29/ 1/2018), Radio La Red (2/11/2018) y Radio Fox Sports (6/11/2018). Estas últimas dos fueron entrevistas sobre temas deportivos. De las radios del interior, la oficialista Cadena 3 de Córdoba fue la que realizó más entrevistas a Macri, en por lo menos cuatro oportunidades. 


\section{Lucía Vincent}

gran novedad fue la utilización de las nuevas tecnologías, en especial, las redes sociales, para la generación de climas favorables de opinión en relación con las decisiones y las motivaciones del gobierno.

\section{El medio estrella: las redes sociales}

El gobierno de Macri se constituyó desde el inicio como un nativo digital. La experiencia previa en la Ciudad de Buenos Aires y en las distintas campañas electorales, le dio a sus colaboradores el conocimiento para hacer de la comunicación a través de las redes sociales el centro de la estrategia comunicacional del gobierno.

Una vez que Macri llegó a la presidencia, la estrategia de comunicación a través de las redes se mantuvo como política central del nuevo gobierno, con el objetivo de lograr una comunicación directa y no mediada con los ciudadanos. Para hacerlo, se creó una estructura, se nombraron responsables y se asignó un presupuesto: bajo la supervisión del jefe de Gabinete, Marcos Peña, se organizó un equipo de 80 personas dentro de la "Subsecretaría de Vínculo con la comunidad", destinada a la comunicación a través de las redes ${ }^{17}$. De manera explícita, los responsables de estas estrategias destacaban el valor y el alcance que les permitían los nuevos medios, frente a los medios tradicionales que estaban, desde esta perspectiva, en retirada. Aquellos que siguieran pensando en los medios tradicionales como los principales interlocutores con el gobierno, se habían quedado en el tiempo, sin entender las nuevas lógicas postindustriales ${ }^{18}$.

17 Durante el primer año de gobierno, el equipo de redes tuvo un presupuesto de $\$$ 163.289.111, el cual se dividió en 87 millones para pauta en redes, 51 millones en servicios, capacitación y tecnología y 24 millones en sueldos (Recalt, 2016). En 2017 el gobierno gastó \$ 63 millones para publicitar la gestión a través de las redes sociales, un 20\% menos que durante el año anterior. De ese total, 40 millones fueron para Facebook. Para los anuncios publicitarios en Google, el gobierno destinó 18 millones, un $61 \%$ menos que en 2016 (Jastreblanksy, 2018). Sobre el uso de bots y trolls durante el gobierno de Macri ver Fernández (2017).

18 Guillermo Riera, subsecretario de Vínculo Ciudadano de la Jefatura de Gabinete hasta abril de 2017, afirmaba: "El gobierno anterior se despidió en 2015 hablando de Clarín, un diario que tira unos cientos de miles de ejemplares. Nosotros sabemos, y desde hace al menos cuatro años hacemos campaña así, que no sirve ese discurso y esa vía de comunicación no es tan clave como parece" (Fernández, 2017). Por su parte, Julián Gallo, Director de Estrategia y Contenido de Redes Sociales de Cambiemos, decía: "El presidente argentino, Mauricio Macri, busca en las redes sociales tener un espacio propio para ofrecer una versión de sí mismo, disponer de una forma directa para comunicarse, expresar sus sentimientos, explicar sus ideas, escuchar a los demás, expandir su identidad personal más allá de la política. (...) La participación de Macri en Internet es una forma más de estar cerca, sin atriles, sin altavoces, sin protocolo" (Gallo, 2016:12-13). 
El foco del gobierno de Macri dejó de estar entonces en dar prioridad a establecer vínculos y lograr adhesiones con los medios tradicionales, para concentrarse en el despliegue de las redes. Cada plataforma, al tener características distintas, le permitió segmentar los públicos y adaptar los mensajes a cada medio, además de potenciar ciertos mensajes replicándolos en las distintas redes. En el muro de Facebook de Macri aparecían, sobre todo, aspectos de la vida privada del presidente, a los que se sumaban relatos e historias de vida de distintos ciudadanos ${ }^{19}$. La utilización de Instagram buscó llegar, fundamentalmente, a los más jóvenes, mostrando imágenes en tiempo real y desde la perspectiva del protagonista: sus seguidores veían el mundo con los ojos del presidente (Slimovich, 2017; Annunziata, 2018; Montero, 2018). Twitter, en cambio, es una plataforma en donde hay un mayor despliegue de la argumentación, aunque reducida y acotada a 280 caracteres por mensaje ${ }^{20}$. El uso que el gobierno hizo de este medio fue, en su mayoría, informativo de sus distintos actos y medidas, como si se tratara de una "gacetilla de prensa" (Amado y Tarullo, 2015). Las redes más argumentativas, como Twitter, contribuyeron a reforzar comunidades endogámicas con poco espacio para las opiniones disidentes, con la consiguiente polarización del espacio público virtual (Calvo, 2015; Aruguete y Calvo, 2020).

Las redes sociales fueron utilizadas por Cambiemos para la comunicación de primicias sobre medidas y estrategias políticas del gobierno ${ }^{21}$. De esta manera, en lugar de mantener el circuito tradicional de darle las primicias a los medios masivos, aprovechaba el alcance que tenían sus redes para instalar los temas con el formato, los tiempos y los contenidos preestablecidos de acuerdo a los objetivos comunicacionales y políticos del gobierno. Los medios tradicionales debían, luego, levantar lo que ya las redes sociales oficialistas habían difundido.

Si bien la característica esencial del mundo digital es la supuesta horizontalidad y la pérdida de asimetría entre emisores y receptores, en la práctica el gobierno de Cambiemos se constituyó como un gran emisor de

19 Del seguimiento de posteos de la cuenta oficial de Facebook del presidente Mauricio Macri, se observa una combinación de imágenes de la vida privada con posteos del vínculo de proximidad con ciudadanos.

20 Del seguimiento sistemático de la cuenta de Twitter de Macri, se destaca que utilizó esta cuenta para anunciar las medidas de gobierno y las actividades protocolares.

21 Entre otras, las redes sociales de Cambiemos difundieron las siguientes primicias: anticipo antes de asumir de cambios en ganancias (8/12/2015); aceptación de la renuncia del juez Norberto Oyarbide (13/4/2016); ampliación del "Estado en tu barrio" (15/8/ 2016); medidas económicas contra la inflación desde una casa de familia (17/4/2018); adelantos de fondos del FMI (29/8/2018); 10.000 créditos Procrear (2/5/2019); fórmula presidencial Mauricio Macri-Miguel Ángel Pichetto para las elecciones 2019 (11/06/ 2019); eliminación del IVA a alimentos (15/8/2019); campaña "30 ciudades en 30 días" (17/9/2019). 
mensajes, que decidió cómo, cuándo y dónde comunicar, sin generar un diálogo efectivo con sus destinatarios, excepto a través de interacciones controladas. En definitiva, en lugar de hacer actos públicos, dirigir un programa de televisión o apelar a las cadenas nacionales, la comunicación no mediada se dio a través del control de las redes sociales.

La hibridez en la estrategia de comunicación de Cambiemos, al combinar tanto elementos del modelo adaptado como del controlado, se vinculó, por un lado, con la necesidad de diferenciarse de las políticas de comunicación del gobierno anterior y de responder a una concepción liberal del rol de los medios en la sociedad, y, por el otro, con la búsqueda de construcción de poder para la cual mantener el control de la comunicación y la polarización con ciertos medios resultaba funcional para los objetivos del gobierno.

Sin embargo, el vínculo personal entre el gobierno y cada ciudadano a través de las redes, no dio espacio a la construcción de relatos colectivos, al reconocimiento de instancias de mediación que sumaran intereses dispares, a la construcción agregada de sentidos y de acuerdos. Esta estrategia de polarización pudo resultar exitosa en determinados momentos para generar ilusión y ganar elecciones, pero no demostró ser la más adecuada en tiempos de adversidad para el gobierno, cuando necesitó ampliar su base de sustentación, lograr consensos sobre el sentido de las decisiones que tomaba y convencer de que, "haciendo lo que hay que hacer", se podía llegar a buen puerto.

\section{Reflexiones finales}

La comunicación que los gobiernos establecen con la ciudadanía a través de los medios, implica una serie de discursos y de prácticas que buscan mantener los climas favorables de opinión de los gobernados hacia las políticas que lleva adelante el gobierno. Más allá de la diversidad de estrategias que gobiernos de distintas épocas y lugares han utilizado para comunicarse con los ciudadanos, el objetivo de este artículo fue proponer que esta diversidad se puede agrupar en dos grandes modelos: el de comunicación adaptada, con gobiernos que siguen la lógica impuesta por los medios para contactarse con la ciudadanía; y el de comunicación controlada, que pretende contrarrestar el poder de los medios para limitar su poder y lograr una comunicación más favorable a sus objetivos.

Esta propuesta de andamiaje teórico fue la guía para analizar el caso de la comunicación del gobierno de Cambiemos, que se acercó al "modelo de comunicación adaptada" en dos aspectos: primero, los discursos presidenciales sobre los medios fueron escasos y en los que las concepciones sobre el 
rol de los medios en la sociedad se acercaron a una visión liberal de la prensa como encargada de controlar las medidas del gobierno. Segundo, en relación con las políticas de radiodifusión, fue un gobierno que resultó afín a los intereses de los grandes medios, derogando medidas del gobierno anterior en materia de regulación y beneficiándolos con la publicidad oficial.

Los discursos y las prácticas del gobierno de Cambiemos supusieron el fin de la guerra contra el periodismo. Más precisamente, con cierto periodismo y medios que habían mantenido una disputa con el gobierno anterior. Ahora bien, la comunicación de Cambiemos implicó la novedosa utilización de las redes sociales para la generación de apoyos y climas de opinión favorables. Frente a la adaptación que suponían los discursos y las prácticas del gobierno a las lógicas mediáticas, el uso de redes pretendió ejercer un control de la comunicación, al tiempo que incluyó una indiferencia hacia los medios tradicionales o una deliberada elusión de estas instancias de mediación. El resultado fue la instalación de una comunicación controlada que no requería de mediaciones, unidireccional y con escasa vocación por convencer a destinatarios diversos a través de la deliberación política. En este sentido, entonces, se mantuvo una guerra contra el periodismo entendido como instancia de mediación y como arena de deliberación pública en una democracia.

Este artículo pretendió realizar una contribución a las investigaciones sobre medios, política y democracia en dos sentidos: teórico y empírico. A partir de una propuesta teórica en diálogo con distintas investigaciones, este artículo propuso una tipología que permite comprender las características que asumen los vínculos de los gobiernos con los medios y con la sociedad en las democracias actuales. A través del análisis en profunidad de un caso en particular, se acumuló evidencia empírica para establecer futuras comparaciones. Así, el análisis de este caso abre preguntas para nuevas investigaciones. La tipología propuesta por la cual la comunicación de los gobiernos puede dividirse en dos grandes modelos, podría ponerse a prueba para nuevos casos de estudio, en la Argentina y en otros países, que permitan robustecer estas categorías y determinar las causas por las cuales se producen estas diferencias. En particular, la injerencia cada vez mayor de las redes sociales en las formas de hacer política resulta un problema de investigación que demanda de mayores exploraciones. 


\section{Referencias bibliográficas}

Abrevaya, S. (2017). Ahora al cuartel con la satisfacción del deber cumplido. Página/ 12, 12 de julio. . Recuperado de: https:/www.pagina 12.com.ar/49589-ahora-alcuartel-con-la-satisfaccion-del-deber-cumplido

Abrevaya, S. (2015). No va a subsistir. Página/12, 13 de diciembre. Recuperado de: https:/www.pagina12.com.ar/diario/elpais/1-288151-2015-12-13.html

Abrevaya, S. (2015). Un DNU de fin de año para ayudar a los amigos. Página/12, 31 de diciembre. Recuperado de: https:/www.pagina12.com.ar/diario/elpais/1289359-2015-12-31.html

Amado, A. y Tarullo, R. (2015). Tuitear para agendar: el uso de Twitter como gacetilla de prensa en la comunicación gubernamental. Revista Mexicana de Opinión Pública, 19, 127-145.

Annunziata, R. (2018). Si viene, yo lo voto: la proximidad en timbreos y visitas de Mauricio Macri durante la campaña electoral y su primer año de gobierno (20152016). Austral Comunicación, 7 (1), 57-90.

Anria, S. y Vommaro, G. (2020). En Argentina, un giro a la derecha que no fue y el improbable regreso del peronismo de centro-izquierda. Más poder local, 40, 6-10.

Aruguete, N. y Calvo, E. (2020). Fake News, Trolls y otros encantos. Cómo funcionan (para bien y para mal) las redes sociales. Buenos Aires: Siglo XXI.

Becerra, M. (2010). "Las noticias van al mercado: etapas de la intermediación de lo público en la historia de los medios en Argentina”. En Lugones, G. y Flores, J. (Comps.), Intérpretes e interpretaciones de la Argentina en el bicentenario. Bernal: Universidad Nacional de Quilmes.

Becerra, M. (2016). Restauración: cambios en las políticas de comunicación. Revista Epocas, abril. Disponible en: http://revistaepocas.com.ar/restauracion-cambiosen-las-politicas-de-comunicacion/

Blanco, D. y Germano, C. (2005). 20 años de medios y democracia en la Argentina. Buenos Aires: La Crujía.

Califano, B. (2018). La regulación de la comunicación durante el primer año de gobierno de Mauricio Macri. Intersecciones en Comunicación, 12, 49-74.

Calvo, E. (2015). Anatomía política de Twitter en Argentina. Tuiteando \#Nisman. Buenos Aires: Capital Intelectual.

Castells, M. (1999). La era de la información. Ciudad de México: Siglo XXI.

Crettaz, J. (2015). Con un DNU el gobierno disuelve la AFSCA y cambia la ley de medios. La Nación, 31 de diciembre. Recuperado de: https://www.lanacion.com.ar/ politica/con-un-dnu-el-gobierno-disuelve-la-afsca-y-cambia-la-ley-de-mediosnid1858627/

De Diego, J. (2014). “¿Discurso político o politicidad de los discursos?(Una propuesta para pensar la relación entre kirchnerismo y prensa”, en Gindin, I. (Coord) Kirchnerismo, mediatización e identidades políticas: reflexiones en torno a la política, el periodismo y el discurso. Rosario: Editorial de la UNR. 
De Diego, J. y Fernández, M. (2019). Un devenir populista: comunicación política y mediatización en el kirchnerismo. DeSignis, 31, 271-282.

Fabbrini, S. (2009). El ascenso del príncipe democrático. Buenos Aires: Fondo de Cultura Económica.

Fernández, M. (2014). "Periodismo y política en la Argentina(kirchnerista: disputas por la intermediación en el espacio público.(Un análisis desde la perspectiva de la mediatización”, en Gindin, I. (Coord) Kirchnerismo, mediatización e identidades políticas: reflexiones en torno a la política, el periodismo y el discurso. Rosario: Editorial de la UNR.

Fernández, P. (2017), El mundo secreto de los bots y los trolls... (y cómo esos "ejércitos" influyen en la política). Chequeado. Disponible en: www.chequeado.com/.../ el-mundo-secreto-de-los-bots-y-los-trolls

Ferry, J.M. (1992). El nuevo espacio público. Barcelona: Gedisa

Eco, U. (2010). A paso de cangrejo. Madrid: Debate.

Gallo, J. (2016). Sin atriles ni altavoces. Así es la comunicación digital de Macri en Argentina. Más Poder Local, 28, 12-14.

Jastreblanksy, M. (2018). Menos gasto en redes en 2017: \$63 millones. La Nación, 27 de mayo. Recuperado de: https:/www.lanacion.com.ar/politica/menos-gasto-enredes-en-2017-63-millones-nid2138297

Jefatura de Gabinete (2018). Carta sobre Libertad de expresión y medios públicos. Disponible en: https://www.casarosada.gob.ar/slider-principal/42079

Kitzberger, P. (2012). The Media Politics of Latin America's Leftist Governments. Journal of Politics in Latin America, 4/ 3, 123-139.

Kitzberger, P. (2014). "La madre de todas las batallas: el kirchnerismo y los medios de comunicación”, en Malamud, A. y De Luca, M. (Coord.). La política en tiempos de los Kirchner. Buenos Aires: Eudeba.

Landi, O. (1992). Devórame otra vez: qué hizo la TV con la gente, qué hace la gente con la $T V$. Buenos Aires: Planeta.

Manin, B. (1997). Los principios del gobierno representativo. Madrid: Editorial Alianza

Marino, S. y Espada, A. (2017). ¿Cómo usó la publicidad oficial Macri en su primer año? Chequeado. Disponible en: chequeado.com/el-explicador/como-uso-la-publicidad-oficial-macri-en-su-primer-ano

Mazzoleni, G. (2008). "Populism and the Media”, en Albertazzi, D. y Mc Donnel, D. (ed.), Twenty-First Century Populism. The Spectre of Western European Democracy. New York: Palgrave Macmillan.

Mochkofsky, G. (2011). Pecado original. Clarín, los Kirchner y la lucha por el poder. Buenos Aires: Planeta.

Montero, A.S. (2018). Gestionar la duda. La interpelación al paradestinatario en el discurso de Cambiemos (Argentina). Revista Mexicana de Opinión Pública , 13 (25), 41-61.

Morresi, S. (2015). “Acá somos todos democráticos: el PRO y las relaciones entre la derecha y la democracia en Argentina”, en Vommaro, G. y Morresi, S. (Comps.), 


\section{Lucía Vincent}

Hagamos equipo, PRO y la construcción de la nueva derecha en Argentina. Buenos Aires: UNGS, 163-201.

O’Donnell, G. (1994). Delegative Democracy. Journal of Democracy, 5, (1), 55-69.

O’Donnell, G. (2002). “Acerca de varias accountabilities y sus interrelaciones”, en Peruzzoti, E. y Smulovitz, C. (Ed.), Controlando la política: ciudadanos y medios en las nuevas democracias latinoamericanas. Buenos Aires: Temas.

Panizza, F. (2009). El populismo como espejo de la democracia. Buenos Aires: FCE.

Pérez-Liñán, A. (2009). Juicio político al presidente y nueva inestabilidad política en América Latina. Buenos Aires: FCE.

Quevedo, L.A. (1999). “Política, medios y cultura en la Argentina de fin de siglo”, en Filmus, D. (Ed). Los noventa. Política, sociedad y cultura en América Latina y Argentina de fin de siglo. Buenos Aires: Eudeba-Flacso.

Recalt, R. (2016). El gobierno gasta \$160 millones al año en redes sociales. Revista Noticias, 17 de agosto. Recuperado de: https://noticias.perfil.com/noticias/general/2016-08-17-como-funcionan-las-redes-sociales-del-pro.phtml

Rossi, D. (2009). "La radiodifusión entre 1990-1995: exacerbación del modelo privado-comercial", en Mastrini, G. (Ed.). Mucho ruido, pocas leyes: economía y políticas de comunicación en la Argentina 1920-2007. Buenos Aires: La Crujía.

Ruiz, F. (2008). La democracia editada: 25 años de periodismo y democracia en Argentina 1983-2008. Temas de Comunicación, 16, 89- 107.

Sarlo, B. (1996). Instantáneas: medios, ciudad y costumbres en el fin de siglo. Buenos Aires: Ariel.

Sartori, G. (1998). Homo Videns, la sociedad teledirigida. Madrid: Taurus.

Schuliaquer, I. (2014). Los cambios en la escena mediática sudamericana: los gobiernos progresistas(y los grandes grupos comunicacionales. Horizontes Latinoamericanos, 3, (1), 49-60.

Slimovich, A. (2017). La ruta digital a la presidencia argentina. Un análisis político e hipermediático de los discursos de Mauricio Macri en las redes sociales. Dixit, 26, 24-43.

Verón, E. (1986). La mediatización. Buenos Aires: Facultad de Filosofía y Letras, UBA. Vommaro, G. (2008). Mejor que decir es mostrar. Medios y política en la democracia argentina. Buenos Aires: UNGS/Biblioteca Nacional.

Vommaro, G., Morresi, S. y Bellotti, A. (2015). Mundo Pro. Anatomía de un partido fabricado para ganar. Buenos Aires: Planeta.

Vincent, L. (2011). La disputa por la mediación durante el kirchnerismo. Confines de Relaciones Internacionales y Ciencia Política, 7, (13), 49-81.

Vincent, L. (2017). El kirchnerismo y los medios: entre el control y la polarización. Temas y Debates, 34, (21), 101-124.

Waisbord, S. (2000). Watchdog journalism in South America: news, accountability, and democracy. New York: Columbia University Press.

Waisbord, S. (2014). Vox populista. Medios, periodismo, democracia. Buenos Aires: Gedisa. 


\title{
Recursos electrónicos
}

Sitio web oficial de la Casa Rosada, sección discursos: www.casarosada. gob.ar/ informacion/discursos. Discursos descargados entre 2018 y 2019.

\section{Palabras Clave}

Medios de comunicación — gobiernos — discursos públicos — redes sociales - Cambiemos

\section{Keywords}

Mass media - governments - public speeches - social media - Cambiemos

\begin{abstract}
The government of Cambiemos in Argentina (2015-2019) developed a communication strategy adapted to the logic of the main media, which was a contrast to the controlled communication model of the Kirchner governments. However, the novel use of social media involved a search for control of communication, the installation of topics on the agenda, the choice of messages, platforms and audiences, while including an avoidance of traditional media, especially, of the opponents. This communication strategy, far from appeasing the political and media polarization, maintained it. To test this hypothesis, this article is based on presidential speeches, newspaper publications, government measures on broadcasting and monitoring of social media. Through the study of this case, the article seeks to contribute to research on the relationship between governments and the media and its impact on democracy.
\end{abstract}

